\title{
Using PyC modified 3D carbon fiber to reinforce UHTC under low temperature sintering without pressure
}

\author{
Baihe $\mathrm{DU}^{a}$, Yuan $\mathrm{CHENG}^{a,{ }^{*}}$, Liancai XUN ${ }^{a}$, Shuchang $\mathrm{ZHANG}^{a}$, Jing $\mathrm{TONG}^{a}$, \\ Qingrong $\mathrm{LV}^{b}$, Shanbao $\mathrm{ZHOU}^{a}$, Ping $\mathrm{HU}^{a,{ }^{*}}$, Xinghong $\mathrm{ZHANG}^{a}$ \\ ${ }^{a}$ National Key Laboratory of Science and Technology on Advanced Composites in Special Environments, and Center \\ for Composite Materials and Structures, Harbin Institute of Technology, Harbin 150001, China \\ ${ }^{b}$ School of Physics and Material Science, Anhui University, Hefei 230601, China
}

Received: April 1, 2021; Revised: April 18, 2021; Accepted: May 6, 2021

(C) The Author(s) 2021.

\begin{abstract}
Finding the optimum balance between strength and toughness, as well as acquiring reliable thermal shock resistance and oxidation resistance, has always been the most concerned topic in the discussion of ultra-high temperature ceramic composites. Herein, PyC modified 3D carbon fiber is used to reinforce ultra-high temperature ceramic (UHTC). The macroscopic block composite with large size is successfully fabricated through low temperature sintering at $1300{ }^{\circ} \mathrm{C}$ without pressure. The prepared $\mathrm{PyC}$ modified $3 \mathrm{D} \mathrm{C}_{\mathrm{f}} / \mathrm{ZrC}-\mathrm{SiC}$ composites simultaneously possess excellent physical and chemical stability under the synergistic effect of $\mathrm{PyC}$ interface layer and low temperature sintering without pressure. The fracture toughness is increased in magnitude to $13.05 \pm 1.72 \mathrm{MPa} \cdot \mathrm{m}^{1 / 2}$ accompanied by reliable flexural strength of $251 \pm 27 \mathrm{MPa}$. After rapid thermal shock spanning from room temperature (RT) to $1200{ }^{\circ} \mathrm{C}$, there are no visible surface penetrating cracks, spalling, or structural fragmentation. The maximum critical temperature difference reaches $875{ }^{\circ} \mathrm{C}$, which is nearly three times higher than that of traditional monolithic ceramics. The haunting puzzle of intrinsic brittleness and low damage tolerance are resolved fundamentally. Under the protection of PyC interface layer, the carbon fibers around oxide layer and matrix remain structure intact after static oxidation at $1500{ }^{\circ} \mathrm{C}$ for $30 \mathrm{~min}$. The oxide layer has reliable physical and chemical stability and resists the erosion from fierce oxidizing atmosphere, ensuring the excellent oxidation resistance of the composites. In a sense, the present work provides promising universality in designability and achievement of 3D carbon fiber reinforced ceramic composites.
\end{abstract}

Keywords: ultra-high temperature ceramic (UHTC); pyrolytic carbon interface layer; carbon fiber

\section{Introduction}

Near-space hypersonic flight has been universally

* Corresponding authors.

E-mail: Y. Cheng, cy6810@hit.edu.cn;

P. Hu, huping@hit.edu.cn acknowledged as the most complex and dangerous area from scientific and engineering perspectives, turning into an extremely aerodynamic thermal environment [1-3]. Undoubtedly, thermal protection materials used for key structures, such as nose cones, leading edges, and engine combustion chambers, require both excellent physical and chemical stability to meet rigorous 
requirements [4-6]. The materials need to possess reliable mechanical properties, stable coordination between macro- and micro-deformation during rapid heating and cooling, and strong bonding between the oxide layer and matrix material undergoing high-speed airflow scour [7].

Refractory metals and their alloys, oxidation resistance modified $\mathrm{C} / \mathrm{SiC}$ or $\mathrm{C} / \mathrm{C}$ composites, ultrahigh temperature ceramics (UHTCs) and their composites are popular candidates for thermal protection materials [8-13]. Refractory metals and their alloys normally exhibit ideal high-temperature performance, but oxidation ablation resistance could be improved. In addition, it is challenging to achieve a high density of these materials, and their high cost objectively limits their future development [14]. The upper-temperature limit of $\mathrm{C} / \mathrm{SiC}$ composites is about $1600{ }^{\circ} \mathrm{C}$, while $\mathrm{C} / \mathrm{C}$ composites have poor oxidation resistance $[15,16]$. Thus, it is common to incorporate a high-temperature ceramic phase with excellent oxidation resistance performance to improve the high-temperature behavior and oxidation resistance properties of the matrix phase [17]. However, the control of high-temperature ceramic composition and content in a wide range is hardly to achieve [18]. It is mostly confined to carbide precursors, such as $\mathrm{ZrC}$ or HfC, being usually less than $10 \mathrm{vol} \%[19,20]$. As a result, particles of the high-temperature ceramics randomly disperse inside the $\mathrm{C} / \mathrm{SiC}$ or $\mathrm{C} / \mathrm{C}$ composites, hindering the formation of a dense oxide layer that can resist intense external oxidation. Moreover, dozens of impregnation and pyrolysis steps at temperatures over $1500{ }^{\circ} \mathrm{C}$ would damage the carbon fibers and inhibit the strengthening and toughening effect [21]. The introduction of high-temperature ceramic coatings on $\mathrm{C} / \mathrm{SiC}$ or $\mathrm{C} / \mathrm{C}$ composites' surface could also prevent direct contact with oxygen and improve the working temperature and oxidation resistance [22,23]. Nevertheless, incorporating high-temperature ceramic coatings would yield thermal mismatching and consequent delamination in the high dynamic pressure environment [24].

Due to the extremely high melting point (over $3000{ }^{\circ} \mathrm{C}$ ), excellent oxidation and ablation resistance, UHTCs and their composites are generally accepted for using in oxidation environments above $1800{ }^{\circ} \mathrm{C}$, retaining non-ablation characteristics and structural integrity [25-29]. However, the main obstacle toward engineering applications of UHTCs is symmetrically distributed strong covalent bonds, which lead to intrinsic brittleness and low damage tolerance [30].
Thus, strengthening and toughening are among the most important research topics related to UHTCs, aiming to find an optimal balance between strength and toughness, with stable thermal shock resistance and oxidation resistance at the same time. Scientists and engineers investigated many approaches, such as particle toughening [31,32], soft graphite phase toughening $[33,34]$, whisker toughening $[35,36]$, and fiber toughening $[37,38]$, to induce crack deflection and bifurcation and inhibit the crack tip propagation. Among these toughening phases, three-dimensional (3D) carbon fibers were considered the most promising material due to excellent room and high-temperature mechanical properties, continuously providing a strengthening and toughening skeleton. The incorporation of UHTCs and SiC into three-dimensional carbon fibers has gradually become a developmental trend and a research hotspot worldwide $[39,40]$. Still, this approach objectively faces some scientific and technical challenges. The most urgent problem is to achieve uniform introduction, stacking, and sintering of high content of UHTCs with arbitrary components and particle sizes inside 3D carbon fibers at a low temperature without pressure [41]. This prevents UHTCs and $\mathrm{SiC}$ from forming a double continuous distribution inside the $3 \mathrm{D}$ carbon fibers, yielding unreliable physical and chemical stability. Furthermore, an in-situ oxide layer poorly binds to the matrix material, and it may easily fail under high dynamic pressure. Moreover, it is difficult to overcome the thickness constraint due to the size effect, inevitably yielding high porosity of final composite, visible to the naked eyes. The most challenging from the engineering perspective is to prepare large macroscopic block composites. Furthermore, macrostructural and/or microstructural damage of 3D carbon fibers will likely occur under repeated high-temperature treatments, reactive precursor material, and high-temperature alloy during the traditional sintering process [42]. Subsequently, it inhibits the strengthening and toughening of material and aggravates the oxidation corrosion, having a negative impact on the overall functional properties.

Therefore, besides pressureless low-temperature preparation, an appropriate interface layer between carbon fibers and a ceramic matrix is necessary to protect the carbon fibers from chemical corrosion during the high-temperature pressure sintering. Therefore, in this paper, a pyrolytic carbon interface layer was introduced onto the surface of carbon fibers by 
chemical vapor deposition, and a macroscopic block PyC-3D $\mathrm{C}_{\mathrm{f}} / \mathrm{Zr}-\mathrm{SiC}$ composite with a large size was prepared by low temperature pressureless sintering. We systematically studied the synergistic effect of the PyC interface layer and low temperature pressureless sintering on the carbon fiber microstructure protection and the related influence on flexural strength, fracture toughness, thermal shock resistance, and static oxidation properties. Furthermore, this work provides theoretical and technical support for the synergy of strengthening, toughening, and oxidation resistance of 3D carbon fiber-reinforced UHTC composites, which propels the engineering applications of thermal protection materials in key structures for hypersonic flight vehicles.

\section{Experiment}

\section{1 Raw materials}

The 3D needled carbon fabric was purchased from Jiangsu Tian-niao Hi-Tech Co., Ltd., China. The ZrC powders with an average particle size of $200 \mathrm{~nm}$ and a purity of $99.5 \%$ were commercially available in Beijing HWRK Chem. Co., Ltd., China. The liquid polycarbosilane with an average relative molecular mass around 3000 was bought from National University of Defense Technology, China. All the raw materials were of analytical grade and used as received in this work.

\section{2 Preparation method}

The PyC interface layer on the carbon fiber's surface was prepared by chemical vapor deposition process. First, the 3D carbon fiber was put into furnace to ensure not to contact the furnace wall and maintained for $1 \mathrm{~h}$ at $500{ }^{\circ} \mathrm{C}$ to remove the sizing agent. Then the 3D carbon fiber was placed in the middle area of chemical vapor deposition furnace to heat up and inlet a certain amount proportion of propylene and tetrachloromethane under vacuum. It was kept for $15 \mathrm{~h}$ stably after reaching $1000{ }^{\circ} \mathrm{C} / 400 \mathrm{~Pa}$ to deposit $\mathrm{PyC}$ interface. The PyC modified 3D carbon fiber was obtained thereby. The UHTC powders were mixed with $70 \mathrm{vol} \%$ anhydrous ethanol via high-energy ball mill at a rotation speed of $300 \mathrm{r} / \mathrm{min}$ for $1 \mathrm{~h}$ to acquire UHTC slurry with high solid content. Then the obtained UHTC slurry was introduced inside 3D carbon fiber with vibration assisted injection [29]. After being dried completely at room temperature, the $3 \mathrm{D}$ carbon fiber filled by UHTC powders was processed by 8 cycles of vacuum impregnation of liquid polycarbosilane, curing at $200{ }^{\circ} \mathrm{C} / 1 \mathrm{~h}$ and pyrolysis at $1300{ }^{\circ} \mathrm{C} / 1 \mathrm{~h}$ without pressure under vacuum in succession. Finally, the $\mathrm{PyC}$ modified $3 \mathrm{D} \mathrm{C}_{\mathrm{f}} / \mathrm{ZrC}-\mathrm{SiC}$ composite was prepared.

\section{3 Characterization of room temperature flexural strength}

The creep elastic deformation and plastic deformation tester of Instron5569 was used to measure the flexural strength of the material at room temperature. The three-point flexural method was selected as the test method. The specific steps are: (1) The material is processed into $3 \mathrm{~mm} \times 4 \mathrm{~mm} \times 36 \mathrm{~mm}$ size by wire cutting machine; (2) the angle of the processed sample is polished and chamfered $\left(0.1-0.3 \mathrm{~mm} \times 45^{\circ}\right)$ to eliminate stress concentration; (3) the processed samples were put into the test bench, and were tested under the loading rate of $0.5 \mathrm{~mm} / \mathrm{min}$ and $30 \mathrm{~mm}$ span. To reduce the experimental error, the average value of 5-8 samples was selected as the measurement result. The flexural strength of the material is calculated by following Eq. (1) [43]:

$$
\sigma_{\mathrm{b}}=\frac{3 P_{\mathrm{f}} L}{2 h^{2} w}
$$

In the formula, $h(\mathrm{~mm})$ and $w(\mathrm{~mm})$ respectively represent the height and width of the test specimen after cutting and grinding, $P_{\mathrm{f}}(\mathrm{N})$ is the maximum load value when the material is fractured, and $L(\mathrm{~mm})$ refers to the span.

\section{4 Characterization of fracture toughness}

The creep elastic deformation and plastic deformation tester of Instron5569 was used to measure the fracture toughness. The three-point flexural single-side incision beam method was selected as the test method. The specific steps are: (1) The material is processed into $2 \mathrm{~mm} \times 4 \mathrm{~mm} \times 22 \mathrm{~mm}$ size with wire cutting machine, and the notch depth is $2 \mathrm{~mm}$; (2) the angle of the processed sample is polished and chamfered $\left(45^{\circ}\right)$ to eliminate stress concentration; (3) the processed samples were put into the test bench, and were tested at the loading rate of $0.05 \mathrm{~mm} / \mathrm{min}$ and the experimental parameters of $16 \mathrm{~mm}$ span. In order to reduce the experimental error, the average value of 5-8 samples is 
generally selected as the measurement result. The fracture toughness $K_{\mathrm{IC}}\left(\mathrm{MPa} \cdot \mathrm{m}^{1 / 2}\right)$ of the material is calculated by Eq. (2) [44]:

$$
K_{\mathrm{IC}}=Y \frac{3 P L}{2 w h^{2}} \sqrt{a}
$$

In the formula, $h(\mathrm{~mm})$ and $w(\mathrm{~mm})$ respectively represent the height and width of the test specimen after cutting and grinding. $P(\mathrm{~N})$ is the maximum load value of the material when fracture occurs, $L(\mathrm{~mm})$ is the span, $a(\mathrm{~mm})$ is the notch depth of the sample specimen, and $Y$ is the shape factor. In the range of $L / h=4, \quad 0 \leqslant a / h \leqslant 0.6$, the specific value can be calculated by Eq. (3) [44]:

$$
\begin{aligned}
Y= & 1.93-3.07\left(\frac{a}{h}\right)+14.53\left(\frac{a}{h}\right)^{2} \\
& -25.11\left(\frac{a}{h}\right)^{3}+25.80\left(\frac{a}{h}\right)^{4}
\end{aligned}
$$

\section{5 Characterization of work of fracture}

Work of fracture refers to the energy absorbed by a new unit area when a material is subjected to an applied load until it cracks, propagates, and expands in the process of fracture failure. Work of fracture is one of the important indicators to characterize the toughness and damage tolerance of materials. The work of fracture $\gamma$ can be acquired from Eq. (4) [45]:

$$
\gamma=\frac{W}{2(h-a) w}
$$

In the formula, $h(\mathrm{~mm})$ and $w(\mathrm{~mm})$ respectively represent the height and width of the test specimen after cutting and grinding, $a(\mathrm{~mm})$ is the notch depth of the sample, and $W(\mathrm{~N} \cdot \mathrm{m})$ is the area enclosed by the load-displacement curve and abscissa in the material test.

\section{6 Characterization of thermal shock property}

The thermal shock property was characterized by muffle furnace. The specific steps are as follows: (1) The muffle furnace was connected to the power supply and raised the temperature to the thermal shock test temperature; (2) the flexural strength samples with the size of $3 \mathrm{~mm} \times 4 \mathrm{~mm} \times 36 \mathrm{~mm}$ were put into the muffle furnace and held at the test temperature for $15 \mathrm{~min}$ to ensure that the temperature of samples was basically the same as the temperature in the muffle furnace; (3) the samples were taken out and put into a water bath at $25{ }^{\circ} \mathrm{C}$ for cooling; (4) after cooling, the flexural strength of samples was tested and recorded; (5) the critical thermal shock temperature difference of the material was obtained according to ASTM C152504 standard [46].

\section{7 Characterization of static oxidation}

Muffle furnace was used for static oxidation of material. The specific steps are as follows: (1) The muffle furnace was connected to the power supply and raised the temperature to the static oxidation test value; (2) the static oxidation samples were put into the muffle furnace and held at the test temperature for $15 \mathrm{~min}$ to ensure that the temperature of samples was basically the same as the temperature in the muffle furnace; (3) the samples were taken out and put into room temperature to cool after the stated holding time.

\section{8 Characterization of X-ray diffraction analysis (XRD)}

The materials were characterized by Empyrean intelligent $\mathrm{X}$-ray diffractive analyzer manufactured by Panalytical Company in the Netherlands. $\mathrm{Cu}$ target, $\mathrm{K} \alpha(\lambda=0.154 \mathrm{~nm})$, was used to characterize the material at a scanning rate of $5\left(^{\circ}\right) / \mathrm{min}$ under an angular scanning range of $5^{\circ}-90^{\circ}$ at $2 \theta$.

\section{9 Characterization of scanning electron microscopy (SEM) analysis}

Scanning electron microscope HELIOS Nanolab600i manufactured by FEI Company of United States was used to characterize the microstructure. This model carries an EDS spectrometer and a backscatter imaging device (BSE) to analyze the elements of material and the ratios between them. The resolution of ion imaging can reach $4 \mathrm{~nm}$ under the maximum acceleration voltage of $0.5-30 \mathrm{kV}$.

\section{Results and discussion}

Figure 1 shows the SEM micrographs of individually distributed carbon fibers inside the preform before and after the deposition of PyC interface layer, illustrating different perspectives and magnification times. Figures 1(a) and 1(b) represent the microstructure of randomly selected areas inside the 3D carbon fiber before and after deposition. The uniformity of PyC interface layer is quite good, without apparent carbon nodules or 
overlaps. This may originate from small molecular chains of propylene and tetrachloromethane used as precursors, which could homogeneously diffuse inside the intra-fascicular and inter-fascicular areas of 3D carbon fibers with fast permeation. A comprehensive comparison of the SEM micrographs from axial and radial directions, as shown in Figs. 1(c)-1(f), indicates that the PyC interface layer with a uniform thickness around $500 \mathrm{~nm}$ is successfully deposited along the circumferential direction of individually distributed carbon fibers. Moreover, the structure of carbon fibers before and after the deposition remains intact, without any micro-defects seen from both the axial and radial perspectives. A high-magnification micrograph, Fig. 1(g), reveals the layered crystal structure of the $\mathrm{PyC}$ interface. Moreover, there is a gap between the $\mathrm{PyC}$ interface layer and fibers, indicating relatively weak interface bonding, which could be beneficial for the fiber pull-out from interface layer. It is of great significance for enriching the fiber pull-out forms and optimizing the fracture toughness compared with composites without a PyC interface layer.

Figure 2 shows the optical images and SEM micrographs of internal microstructure of $3 \mathrm{D}$ PyC $-\mathrm{C}_{\mathrm{f}} /$ $\mathrm{ZrC}-\mathrm{SiC}$ composite. The macroscopic large block composite is successfully fabricated, exhibiting no macroscopic defects such as macro-pores or cracks visible to naked eyes. The metallic glossy characteristics of cross-section reflect the dense structure inside the composite. At the same time, the outline of carbon fiber bundles along the $z$-direction can be clearly captured on the surface, as shown in Fig. 2(a). A further observation of the internal micro-morphology before and after the preparation spanning different magnifications and areas is conducted. Even when the introduction of $\mathrm{PyC}$ interface layer reduces the porosity of original 3D carbon fiber, it still could be uniformly filled by a high content of ceramic via vibration assisted $\mathrm{ZrC}$ slurry injection and low temperature supplying sintering of $\mathrm{SiC}$ without pressure (Figs. 2(b) and 2(c)). As presented in Figs. 2(d) and 2(e), the individual fibers and ceramic phases are evenly and densely distributed no matter inside or between the fiber bundles. After multiple infiltration-curing-pyrolysis cycles, the original morphology of $z$-direction carbon fibers is well preserved, indicating that the lowtemperature and pressureless preparation method does not change the structural properties of the $z$-direction carbon fiber bundle of the braid instead of traditional dozens of impregnation and pyrolysis at temperatures over $1500{ }^{\circ} \mathrm{C}$ and hot-pressing sintering. In summary, this kind of low-temperature and pressureless preparation approach has a universality, and it can overcome the constraints brought by the size effect and enable the preparation of large-scale macroscopic components.

The intra-fascicular microstructure evolution during densification process is shown in Fig. 3. The $\mathrm{ZrC}$ powder particles are directly introduced into the interspaces
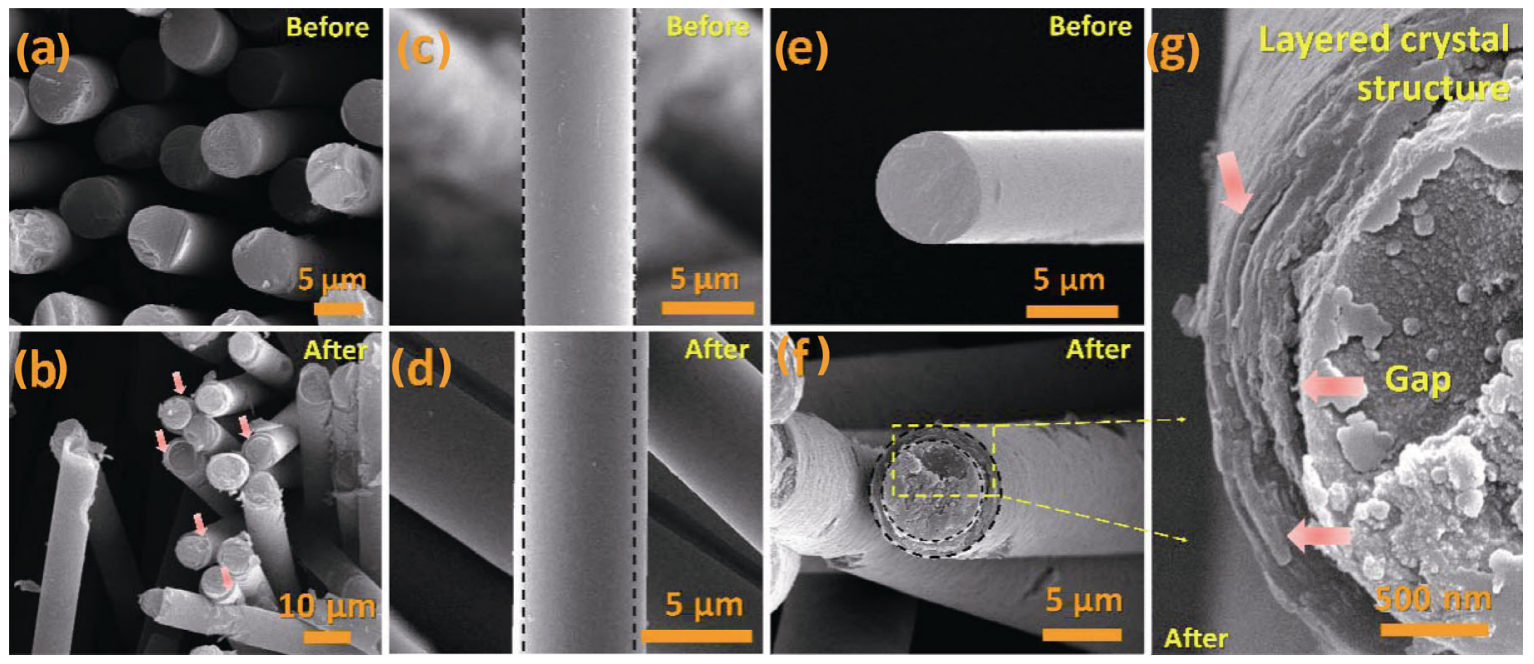

Fig. 1 SEM images of individually distributed carbon fibers inside the preform before and after the deposition of the PyC interface layer, illustrating different perspectives and magnification times: (a) and (b) intrafascicular area; (c) and (d) individually distributed carbon fibers along axial direction; (e) and (f) individually distributed carbon fibers along radial direction; (g) layered crystal structure of PyC interface. 


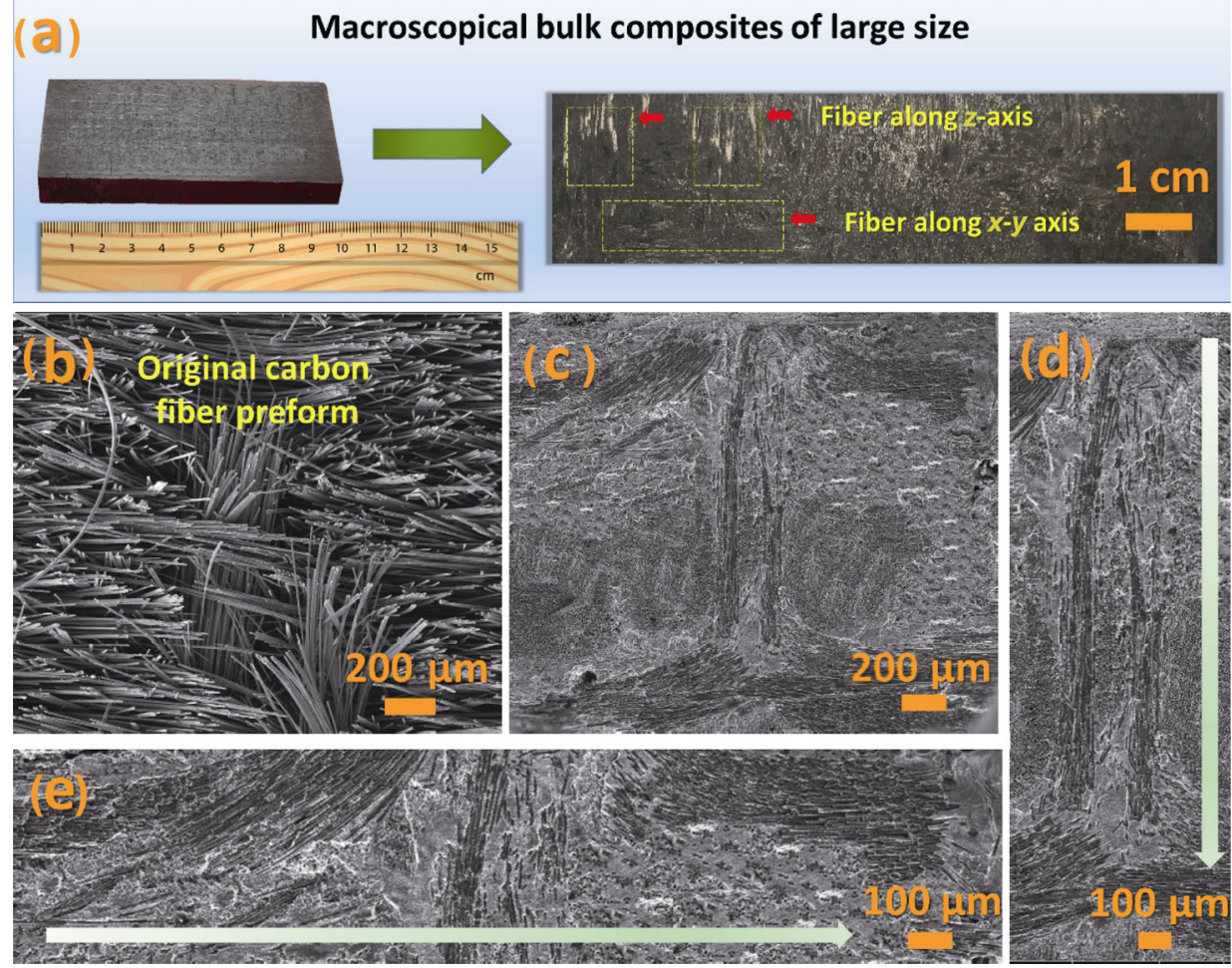

Fig. 2 Optical images and internal microstructure SEM images of 3D PyC- $\mathrm{C}_{\mathrm{f}} / \mathrm{ZrC}-\mathrm{SiC}$ : (a) large-size macroscopical bulk composites; (b) original carbon fiber preform; (c-e) polished surface spanning various magnifications.
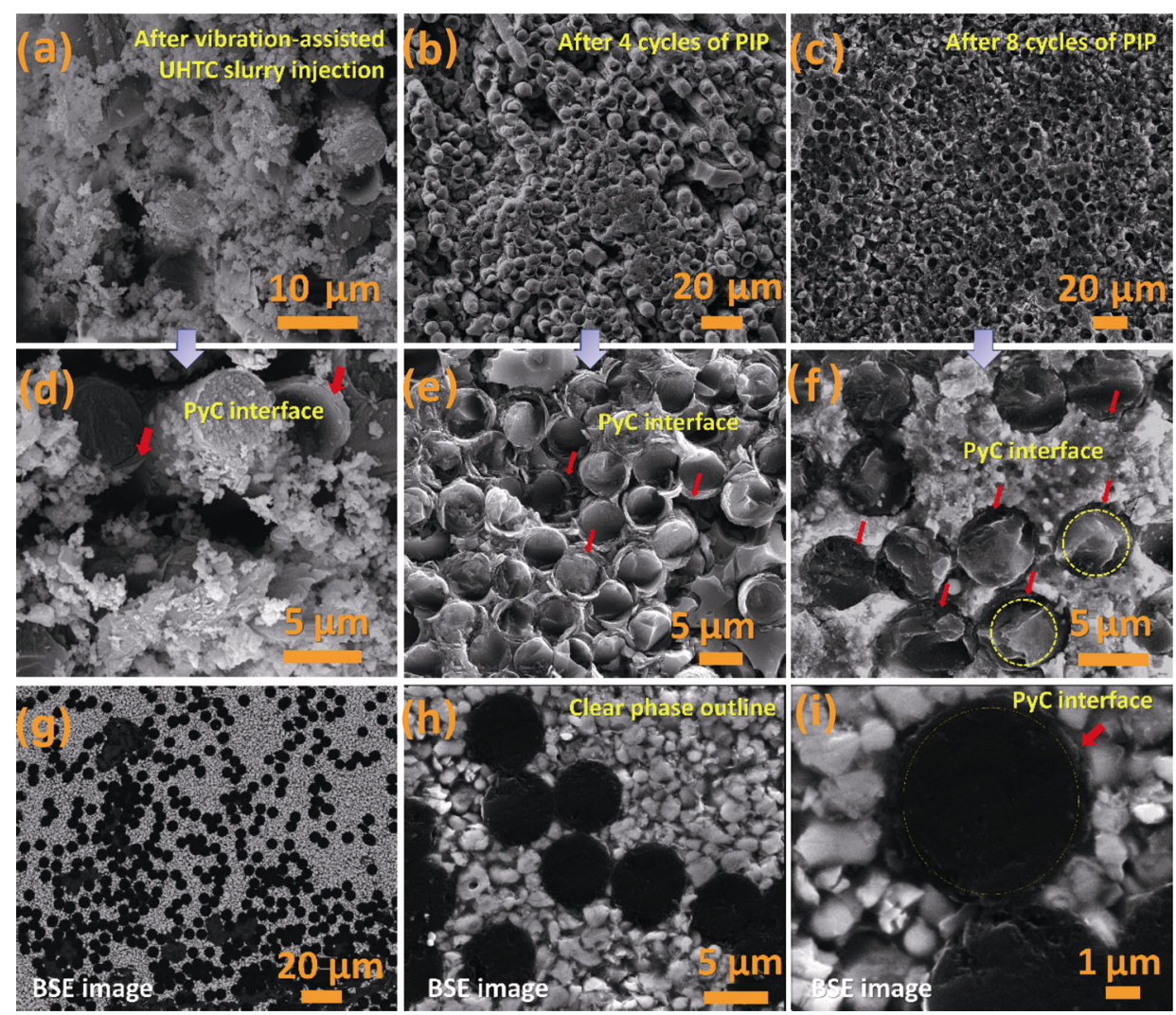

Fig. 3 SEM micrographs of intra-fascicular microstructure evolution during densification process: (a) and (d) after vibrationassisted slurry injection of $\mathrm{ZrC}$; (b) and (e) after 4 cycles of PIP; (c) and (f) after 8 cycles of PIP; (g-i) backscattered-electron (BSE) images for polished surface. 
of independently distributed carbon fibers after vibration-assisted slurry injection with considerable content (Fig. 3(a)). Taking a further observation under higher magnification times, the $\mathrm{ZrC}$ particles tightly wrap around the fibers, as shown in Fig. 3(d). Afterward, the intra-fascicular microstructures after 4 and 8 cycles of polycarbosilane (PCL) infiltrationcuring-pyrolysis are characterized. The SiC ceramic cracked from PCS gradually supplies and fills the intra-fascicular pores left after vibration-assisted slurry injection, which tightly bound the randomly dispersed $\mathrm{ZrC}$ particles in the meantime, thereby yielding a dense microscopic morphology as shown in Figs. 3(b) and 3(d)-3(f). Although the cross-section of carbon fiber shows a certain degree of grain coarsening after repeated infiltration and pyrolysis, the overall structure is well preserved under the protection of the PyC interface layer. Figures 3(g)-3(i) show the backscattered-electron (BSE) micrographs of the final composite with different magnifications. The dark and bright phases refer to carbon fibers and ceramics, respectively. The uniform distribution without apparent porosity could be observed in Fig. 3(g). Under higher magnification as shown in Figs. 3(h) and 3(i), the carbon fibers, $\mathrm{ZrC}$, and $\mathrm{SiC}$ phases are homogeneously dispersed, and the phase boundary between the fibers and ceramic is distinct. The carbon fiber keeps its roundness well and the structure of PyC interface layer is clearly captured. This kind of dense intra-fascicular microstructure with well protected carbon fiber laid strong foundation for reliable strength and toughness [47].

To assess the influence of PyC interface layer on the mechanical properties of the $3 \mathrm{D} \mathrm{C}_{\mathrm{f}} / \mathrm{ZrC}-\mathrm{SiC}$ composite, the mechanical behavior is discussed in detail. While the $3 \mathrm{D}$ PyC $-\mathrm{C}_{\mathrm{f}} / \mathrm{ZrC}-\mathrm{SiC}$ composite has high flexural

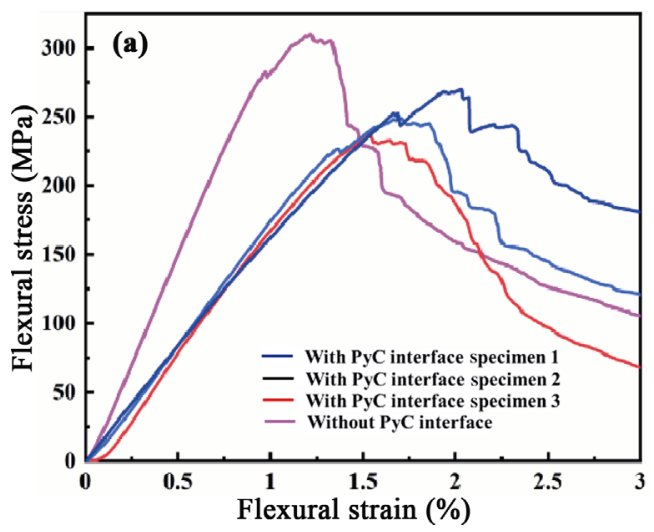

strength $(251 \pm 27 \mathrm{MPa})$, the fracture toughness is further improved $\left(13.05 \pm 1.72 \mathrm{MPa} \cdot \mathrm{m}^{1 / 2}\right)$. This approach may resolve the difficulty of simultaneous implementation of high flexural strength and fracture toughness in UHTCs. Figure 4 shows stress-strain curves and load-displacement curves of $3 \mathrm{D} \mathrm{C}_{\mathrm{f}} / \mathrm{ZrC}-$ $\mathrm{SiC}$ composites with and without $\mathrm{PyC}$ interface layer. The stress-strain curves in Fig. 4(a) all present graceful mode for the reason of utilizing 3D carbon fiber as reinforcement. By comparison, there are obvious differences for composites with and without $\mathrm{PyC}$ interface layer [39]. First of all, the curve after introducing $\mathrm{PyC}$ becomes smoother with slope of linear elastic stage declining, which indicates the decreases in modulus of composite. The modulus mismatch between the carbon fiber and the $\mathrm{ZrC}-\mathrm{SiC}$ ceramic matrix has always been the noteworthy factor impairing the strengthening and toughening, and the $\mathrm{PyC}$ interface layer plays an important role in alleviating the modulus mismatch [48]. Secondly, after introducing the PyC interface layer, the strain corresponding to maximum stress increases from $1.35 \%$ to $1.5 \%-2 \%$, which manifests the improvement of damage tolerance to some degree. Figure 4(b) is a comparison of loaddisplacement curves of the $3 \mathrm{D} \mathrm{C}_{\mathrm{f}} / \mathrm{ZrC}-\mathrm{SiC}$ composite with or without PyC interface layer. Similar to the change of the stress-strain curves, the two composites also experience obvious non-brittle stages. However, after introducing the interface layer, the platform of the nonlinear deformation stage is significantly extended. The displacement corresponding to the maximum load also increases from $0.12 \mathrm{~mm}$ to $0.2-0.3 \mathrm{~mm}$. The load decrease is more gradual, showing obvious zigzag characteristics, indicating that the sensitivity of the composite to crack is significantly reduced.

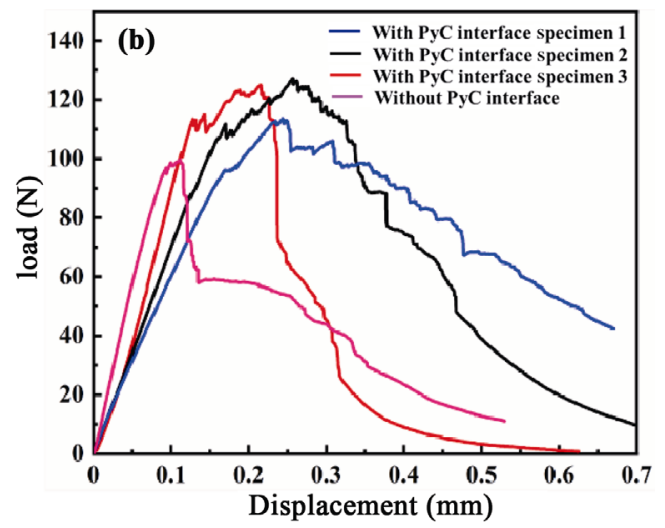

Fig. 4 Stress-strain and load-displacement curves of $3 \mathrm{D} \mathrm{C}_{\mathrm{f}} / \mathrm{ZrC}-\mathrm{SiC}$ composites with and without the PyC interface layer: (a) stress-strain curves; (b) load-displacement curves. 
To analyze and excavate the mechanism behind the promoted mechanical behavior, the fracture microstructures are characterized using SEM from different angles and magnification times as shown in Fig. 5. The side morphology of tested fracture sample is presented in Fig. 5(a), which demonstrates an "S-shaped" fracture track with considerable fiber pull-outs as shown in the yellow box. In the fracture process, stress concentration will cause interface debonding between the fiber and ceramic matrix. The fiber breaks in the case of extensive strain, and the end of the fiber slips and pulls out from the matrix to absorb energy. Therefore, this kind of "S-shaped" fracture track and fiber bundle pull-out indicate that the material would absorb more energy resulting in a significantly enhanced toughness. When taking a further observation, it is found that the $3 \mathrm{D} \mathrm{PyC}-\mathrm{C}_{\mathrm{f}} / \mathrm{ZrC}-\mathrm{SiC}$ composite is more arresting in terms of the number and length of fiber pull-outs than the composite without an interface layer. As shown in Figs. 5(b) and 5(c), the fracture surface appears as fascicular fiber pulled-out with thousands of individual fibers. Moreover, the length of pulled-out carbon fibers is more than $500 \mu \mathrm{m}$. This excellent fiber pull-out performance originates from the low temperature preparation without pressure and the introduction of PyC interface layer. The carbon fibers are effectively protected no matter from the perspective of macroscopical 3D structure or individual distributed one (as shown in Figs. 5(d) and 5(e)), which ensure their original excellent mechanical performances. In addition, the $\mathrm{PyC}$ interface layer also builds up dual weak interfaces of fiber-ceramic matrix and fiber-PyC (as the red arrow pointed in Fig. 5(e)), effectively alleviating the mismatch in the thermal expansion coefficient and modulus. Thereby, the energy consumption during the fracture process is significantly increased by fiber debonding and slippage. The fibers can be solely pulled out from the PyC interface layer or from ceramic matrix together with the interface layer. This kind of multiple forms of fiber pull-out enables the material to absorb more energy, resisting and consuming the external force loading process, thereby enhancing the damage resistance and fracture toughness.

Thermal protection material often encounters rapid heating and cooling during the preparation and service life. Rapid changes in ambient temperature generate transient thermal stress that usually strongly influences the material's surface, posing a severe risk to structural safety. Therefore, the thermal shock resistance is an important indicator of judging the reliability of thermal protection material. In this work, water quenching was used to characterize the thermal shock resistance of 3D $\mathrm{PyC}-\mathrm{C}_{\mathrm{f}} / \mathrm{ZrC}-\mathrm{SiC}$ composite from room temperature (RT) to $1200{ }^{\circ} \mathrm{C}$, and the critical temperature difference of thermal shock was calculated. Figure 6(a) shows the macroscopic photographs of the $3 \mathrm{D} \mathrm{PyC}-\mathrm{C}_{\mathrm{f}} / \mathrm{ZrC}-\mathrm{SiC}$ composite before and after thermal shock at different temperatures. None of the test specimens exhibit visible surface penetration cracks, peeling, or structural cracking. The sample surface appears slightly white when the temperature exceeds $800{ }^{\circ} \mathrm{C}$, which could originate from oxidation of $\mathrm{ZrC}$ ceramic under low temperature
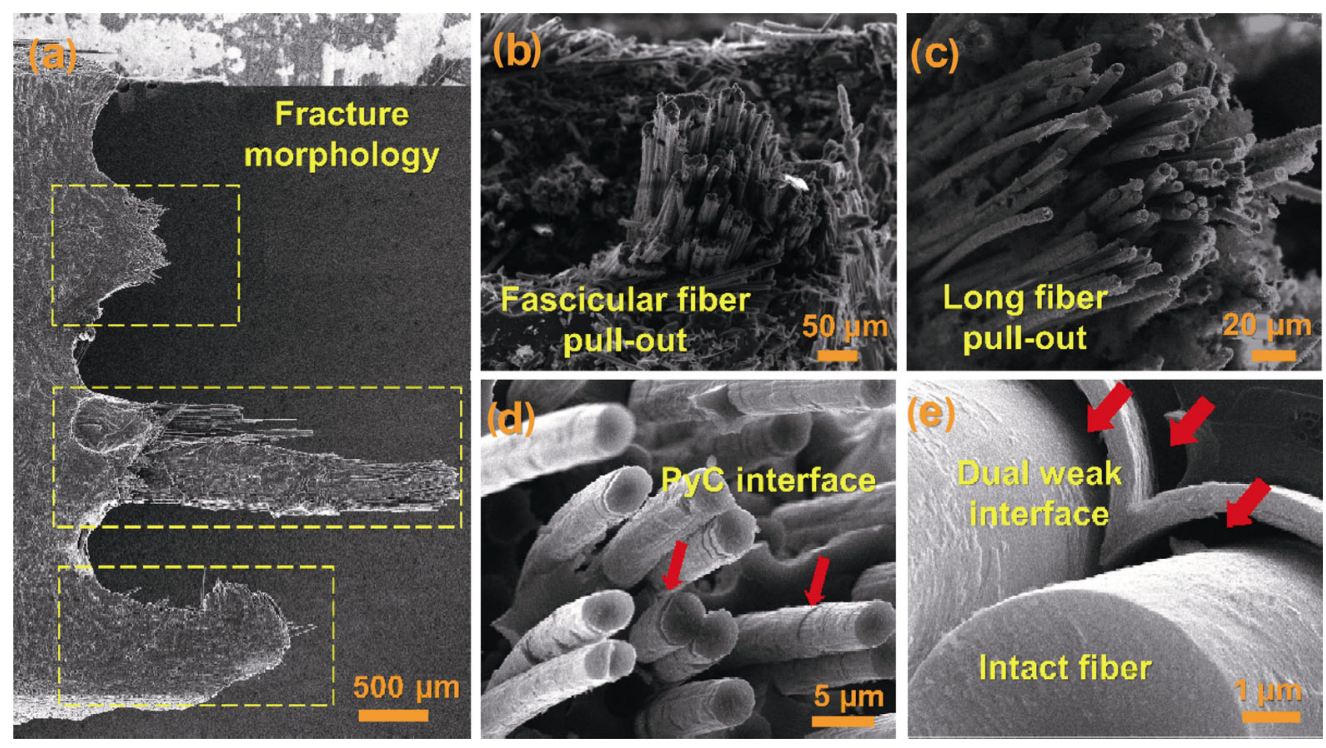

Fig. 5 SEM micrographs of the microstructure of fracture surface: (a) side surface; (b) fascicular fiber pull-out; (c) long fiber pull-out; (d) PyC interface; (e) dual weak interface. 

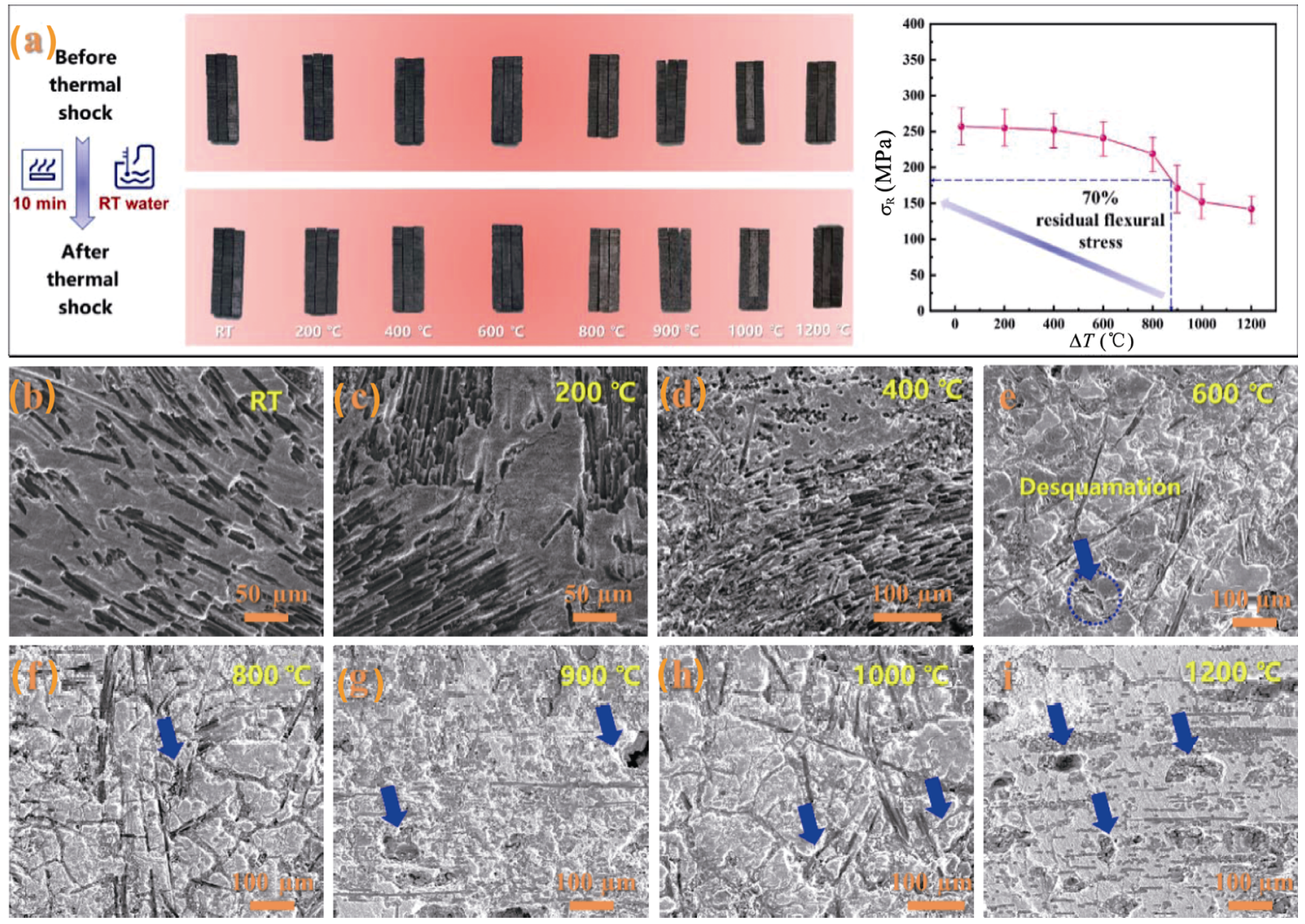

Fig. 6 Thermal shock resistance of 3D PyC- $\mathrm{C}_{\mathrm{f}} / \mathrm{ZrC}-\mathrm{SiC}$ composite and SEM micrographs of the sample surface after thermal shock: (a) photographs of composite before and after the thermal shock at different temperatures from RT to $1200{ }^{\circ} \mathrm{C}$, residual strength $\left(\sigma_{\mathrm{R}}\right)$ as a function of thermal shock temperature difference $(\Delta T)$ of the composite after the thermal shock; (b) RT; (c) $200{ }^{\circ} \mathrm{C}$; (d) $400{ }^{\circ} \mathrm{C}$; (e) $600{ }^{\circ} \mathrm{C}$; (f) $800{ }^{\circ} \mathrm{C}$; (g) $900{ }^{\circ} \mathrm{C}$; (h) $1000{ }^{\circ} \mathrm{C}$; (i) $1200{ }^{\circ} \mathrm{C}$.

(the oxidation starts at $800{ }^{\circ} \mathrm{C}$ ). On the whole, the 3D $\mathrm{PyC}-\mathrm{C}_{\mathrm{f}} / \mathrm{ZrC}-\mathrm{SiC}$ composite can withstand the instantaneous thermal stress generated by thermal shock at wide temperature range spanning from RT to $1200{ }^{\circ} \mathrm{C}$. In comparison, traditional UHTCs are prone to structural damage after the thermal shock at 200-400 ${ }^{\circ} \mathrm{C}$. This confirms the excellent thermal shock resistance of $3 \mathrm{D} \mathrm{PyC}-\mathrm{C}_{\mathrm{f}} / \mathrm{ZrC}-\mathrm{SiC}$ composite.

The flexural strength of samples after the thermal shock was measured to quantitatively evaluate the thermal shock resistance. The critical temperature difference of thermal shock was calculated, and the relationship curve between the residual flexural strength and thermal shock temperature difference was obtained (Fig. 6(a)). The residual flexural strength remains relatively stable in the temperature range from RT to $400{ }^{\circ} \mathrm{C}$. When the thermal shock temperature difference exceeds $400{ }^{\circ} \mathrm{C}$, the residual flexural strength slowly declines, which decreases faster when the temperature exceeds $800{ }^{\circ} \mathrm{C}$. This could be due to the initial oxidation of $\mathrm{ZrC}$ ceramic at $800{ }^{\circ} \mathrm{C}$, lowering the flexural strength to some degree. The calculated critical temperature difference of thermal shock of $3 \mathrm{D}$ PyC $-\mathrm{C}_{\mathrm{f}} / \mathrm{ZrC}-\mathrm{SiC}$ composite is $875{ }^{\circ} \mathrm{C}$, which is nearly 3 times higher than that of traditional UHTC materials, displaying excellent thermal shock resistance. Normally, the strong covalent bonds, low grain boundary, and bulk diffusion rates result in poor thermal shock resistance upon rapid temperature changes. Especially when UHTC is rapidly cooled, the surface undergoes apparent tensile stress, which is more likely to destroy UHTC compared with compressive stress [49]. Figures 6(b)-6(f) show the surface microstructures of $3 \mathrm{D} \quad \mathrm{PyC}-\mathrm{C}_{\mathrm{f}} / \mathrm{ZrC}-\mathrm{SiC}$ composite sample after thermal shock at different temperatures. It is observed that there are almost no surface cracks or peeling of the samples at temperatures from RT to $400{ }^{\circ} \mathrm{C}$ (Figs. 6(b)-6(d)). The fine pores on the samples' surface as shown in Figs. 6(e) and 6(f) are favorable for alleviating the thermal stress during the thermal shock process to some extent and improving the thermal shock resistance as a result. It should be noticed that structure of the carbon fiber remains intact after the thermal shocks at different 
temperatures without oxidation or peeling. This shows that the structural damage of carbon fiber is suppressed under the protection of PyC interface layer, which also explains the reason of improved thermal shock resistance.

Besides the mechanical properties and thermal shock resistance, static oxidation is another important index to analyze and evaluate the physical and chemical stability of UHTC. Figure 7 shows the morphologies and components of $3 \mathrm{D} \mathrm{PyC}-\mathrm{C}_{\mathrm{f}} / \mathrm{ZrC}-\mathrm{SiC}$ composite after static oxidation at $1500{ }^{\circ} \mathrm{C}$ for $30 \mathrm{~min}$. Before the static oxidation, the surface of the 3D $\mathrm{PyC}-\mathrm{C}_{\mathrm{f}} / \mathrm{ZrC}-\mathrm{SiC}$ composite block exhibits glossy metallic reflectance (the macroscopic photograph in the upper right corner of Fig. 7(a)). The microstructural and corresponding EDS results show that after repeated infiltration and pyrolysis of the $\mathrm{SiC}$ ceramic precursor, the main components on the surface are $\mathrm{ZrC}$, $\mathrm{SiC}$, and $\mathrm{C}$ (carbon fibers). After the static oxidation at $1500{ }^{\circ} \mathrm{C}$ for $30 \mathrm{~min}$, the surface shows grayish-white features, as shown in the macroscopic photograph in the upper right corner of Fig. 7(b). And the microstructure of corresponding area appears roughly glassy with EDS analysis of $\mathrm{Zr}, \mathrm{Si}$, and $\mathrm{O}$. The XRD result in Fig. 7(c) indicates the presence of $\mathrm{ZrO}_{2}$ and $\mathrm{SiO}_{2}$ phases on the surface. Therefore, it can be inferred that the oxide layer after the static oxidation at $1500{ }^{\circ} \mathrm{C}$ for $30 \mathrm{~min}$ is mainly composed of $\mathrm{ZrO}_{2}$ and $\mathrm{SiO}_{2}$ phases, which is formed by the oxidation of $\mathrm{ZrC}$ and $\mathrm{SiC}$. Although the $3 \mathrm{D}$ PyC- $\mathrm{C}_{\mathrm{f}} / \mathrm{ZrC}-\mathrm{SiC}$ composite can form a relatively dense oxide layer in most areas after the static oxidation, the oxide layer formed on the local surface is relatively thin with ceramic particles covered by the oxide layer as shown in Fig. 7(d). Besides, there are a few bubbles on the surface (indicated by the red arrow in Fig. 7(d)), which may be caused by the volatilization of $\mathrm{ZrO}_{2}$ from the oxide layer.

To understand the static oxidation behavior of the $3 \mathrm{D} \quad \mathrm{PyC}-\mathrm{C}_{\mathrm{f}} / \mathrm{ZrC}-\mathrm{SiC}$ composite, the microstructural characterization and analysis of the profile after static oxidation were performed. Figure 8 shows the microstructural profile of $3 \mathrm{D} \quad \mathrm{PyC}-\mathrm{C}_{\mathrm{f}} / \mathrm{ZrC}-\mathrm{SiC}$ composite after static oxidation at $1500{ }^{\circ} \mathrm{C}$ for $30 \mathrm{~min}$, demonstrating the overall morphology of oxide layer and composite matrix. Figure $8(\mathrm{a})$ indicates that the oxide layer of the $3 \mathrm{D} \mathrm{PyC}-\mathrm{C}_{\mathrm{f}} / \mathrm{ZrC}-\mathrm{SiC}$ composite mainly consists of a bilayer structure. The outer layer is about $150 \mu \mathrm{m}$, which consists of $\mathrm{ZrO}_{2}$ and $\mathrm{SiO}_{2}$, exhibiting relatively dense microstructure as presented in Fig. 8(b). This kind of dense oxide layer has reliable
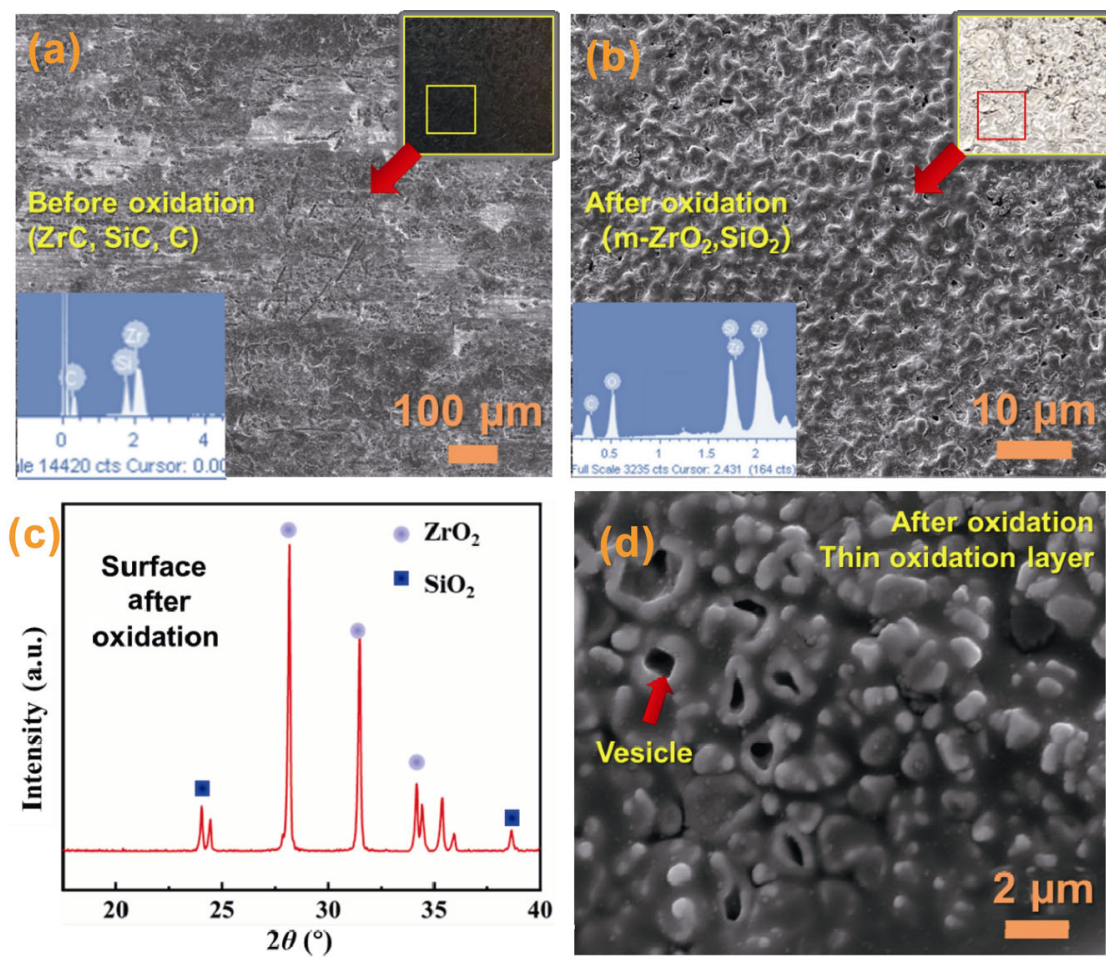

Fig. 7 Macrostructural and microstructural characteristics of the surface of $3 \mathrm{D}$ PyC $-\mathrm{C}_{\mathrm{f}} / \mathrm{ZrC}-\mathrm{SiC}$ composites before and after oxidation at $1500{ }^{\circ} \mathrm{C}$ for 30 min with EDS and XRD analyses: (a) before oxidation; (b) after oxidation; (c) XRD of surface after oxidation; (d) thin $\mathrm{SiO}_{2}$ layer and EDS analysis. 


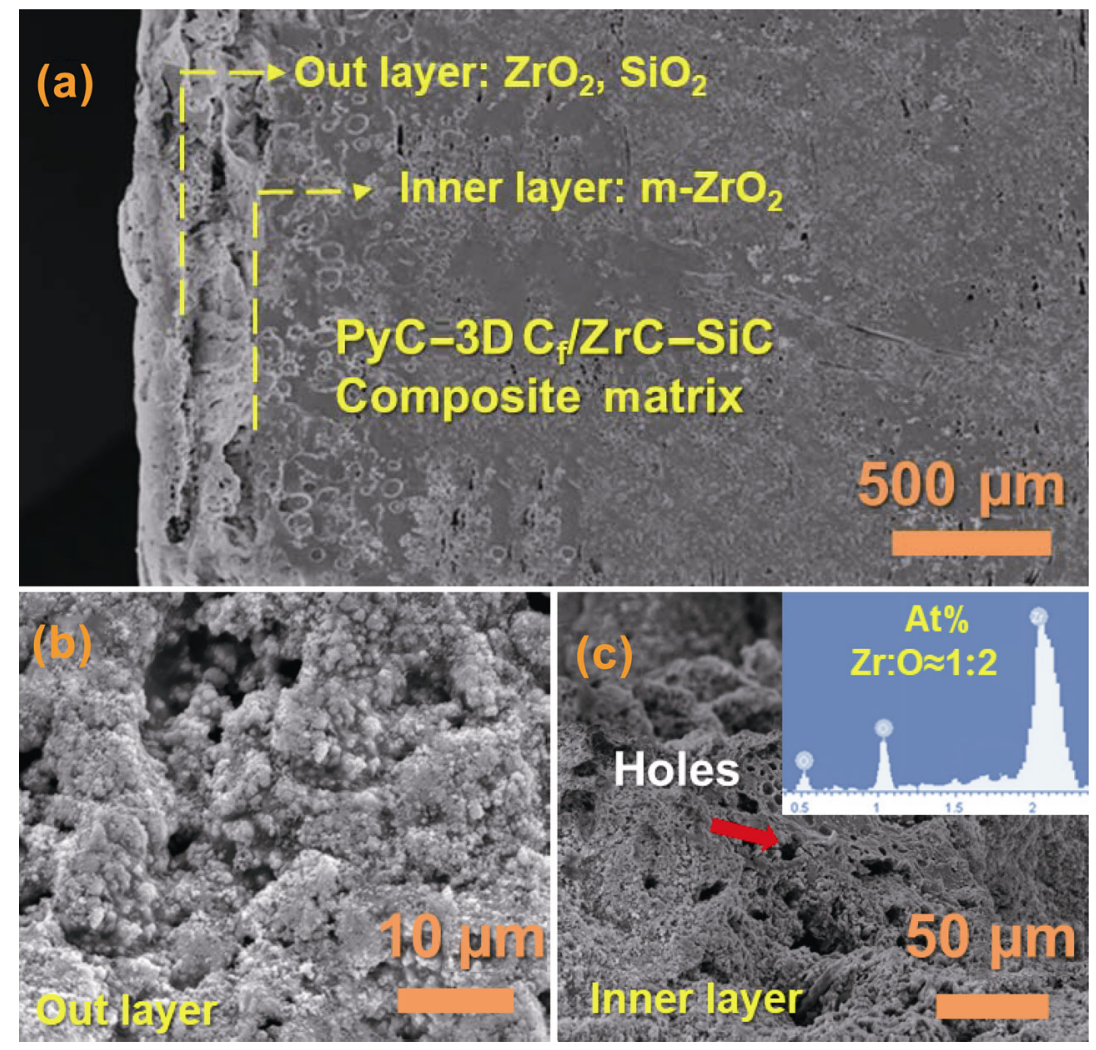

Fig. 8 SEM micrographs of the oxide layer of $\mathrm{PyC}-3 \mathrm{D} \mathrm{C} \mathrm{C}_{\mathrm{f}} / \mathrm{ZrC}-\mathrm{SiC}$ composite after the oxidation at $1500{ }^{\circ} \mathrm{C}$ for $30 \mathrm{~min}$ : (a) overall profile; (b) random out layer area; (c) random inner layer area.

physical and chemical stability and resists the erosion from fierce oxidizing atmosphere, ensuring the excellent oxidation resistance of the composites. Combined with the EDS analysis results (the ratio of atomic numbers), it could be concluded that the inner layer is composed of $\mathrm{ZrO}_{2}$, with a thickness of about $170 \mu \mathrm{m}$. It appears as a particle stacking structure, with some holes in Fig. 8(c). Below the oxide layer is the $3 \mathrm{D}$ PyC $-\mathrm{C}_{\mathrm{f}} / \mathrm{ZrC}-\mathrm{SiC}$ composite matrix. The oxide layer protects the matrix, and the presence of the $z$-direction carbon fiber structure can be clearly observed in Fig. 8(a).

During the static oxidation process, $\mathrm{ZrC}$ and $\mathrm{SiC}$ are first oxidized to produce $\mathrm{ZrO}_{2}$ and $\mathrm{SiO}_{2}$ due to the sufficient oxygen partial pressure. As oxygen atoms gradually diffuse into the interior of composite, the inner layer starts to oxidize. The carbon fibers oxidize to $\mathrm{CO}$ and $\mathrm{CO}_{2}$ gases, $\mathrm{SiC}$ yields $\mathrm{SiO}_{2}$, while $\mathrm{ZrC}$ forms $\mathrm{ZrO}_{2}$. The rapid oxidation and depletion of carbon fibers and $\mathrm{SiC}$ in the inner layer result in stacking particle morphology. Figure $8(\mathrm{~b})$ shows the holes that remained after the fiber oxidation. With the prolonged oxidation, the liquid phase $\mathrm{SiO}_{2}$ content of surface gradually increases. The liquid $\mathrm{SiO}_{2}$ phase promotes the $\mathrm{ZrO}_{2}$ sintering and partly fills the pores formed by the $\mathrm{ZrO}_{2}$ volatilization, so that the protective ability of the outer oxide layer is gradually enhanced, forming a relatively dense structure [50]. Figure 9 shows the micro-morphology of carbon fiber in the transition region between the oxide layer of the 3D $\mathrm{PyC}-\mathrm{C}_{\mathrm{f}} / \mathrm{ZrC}-\mathrm{SiC}$ composite and the matrix after the static oxidation. Although the carbon fiber is oxidized to a certain extent, the fiber's structure is well preserved by the sacrifice and protection of $\mathrm{PyC}$ interface layer, exhibiting no traces of severe corrosion. This shows that the PyC interface layer provides protection to the carbon fiber during the static oxidation experiment at $1500{ }^{\circ} \mathrm{C}$ for $30 \mathrm{~min}$.

\section{Conclusions}

In this study, PyC modified 3D carbon fiber was utilized to reinforce UHTC. The macroscopic bulk composite is successfully fabricated through low temperature sintering at $1300{ }^{\circ} \mathrm{C}$ without pressure. The $\mathrm{PyC}$ interface layer not only constructed protective barrier for carbon fiber, but also introduced weak 


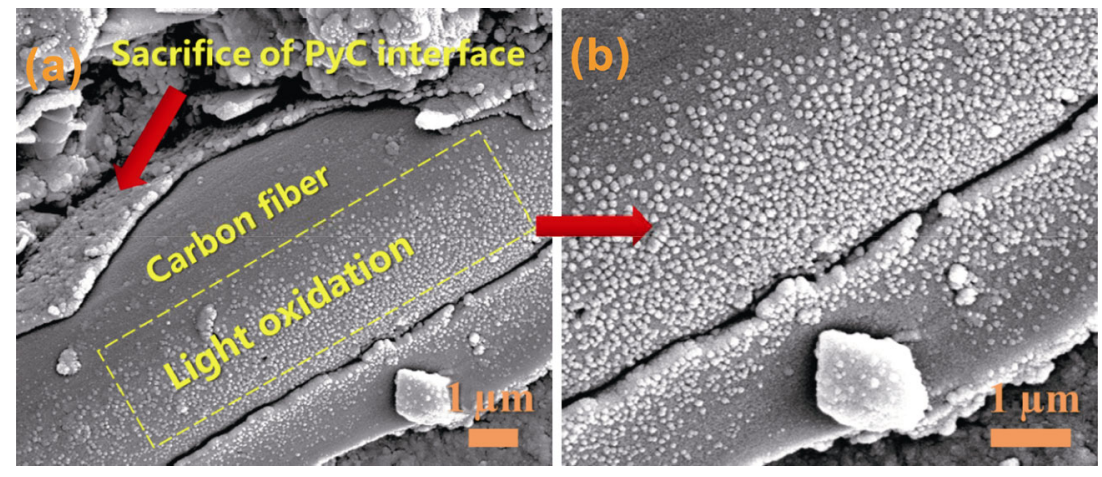

Fig. 9 Microstructures of the carbon fiber on the $3 \mathrm{D}$ PyC $-\mathrm{C}_{\mathrm{f}} / \mathrm{ZrC}-\mathrm{SiC}$ composite surface after the static oxidation at $1500{ }^{\circ} \mathrm{C}$ for 30 min: (a) low magnification times; (b) high magnification times

interface layer between individual fiber and ceramic matrix. As a result, it effectively alleviated the mismatch of thermal expansion coefficient and modulus between fiber and ceramic matrix, and stimulated toughening mechanisms, such as interface debonding, crack deflection, crack bridging, and fiber pull-out. The low temperature sintering at $1300{ }^{\circ} \mathrm{C}$ without pressure could overcome the constraints brought by the size effect and enable the fabrication of large-scale bulk components. Moreover, it has great universality to achieve the uniform introduction, stacking, and sintering of high content of UHTCs with arbitrary components and particle sizes inside 3D carbon fibers at low temperature without pressure. Under the synergistic effect of PyC interface layer and low temperature sintering without pressure, the prepared $3 \mathrm{D}$ PyC $\mathrm{C}_{\mathrm{f}} / \mathrm{ZrC}-\mathrm{SiC}$ composites simultaneously possesses reliable fracture toughness at $13.05 \pm 1.72 \mathrm{MPa} \cdot \mathrm{m}^{1 / 2}$ and flexural strength at $251 \pm 27 \mathrm{MPa}$. After rapid thermal shock spanning from RT to $1200{ }^{\circ} \mathrm{C}$, there are no visible surface penetrating cracks, spalling or structural fragmentation. The maximum critical temperature difference reaches $875{ }^{\circ} \mathrm{C}$, which is nearly three times higher than that of traditional monolithic ceramics. The haunting puzzle of intrinsic brittleness and low damage tolerance are resolved fundamentally. The carbon fibers around oxide layer and matrix remains structure intact after static oxidation at $1500{ }^{\circ} \mathrm{C}$ for $30 \mathrm{~min}$. The oxide layer has reliable physical and chemical stability and resists the erosion from fierce oxidizing atmosphere, ensuring the excellent oxidation resistance of the composites. This work not only breaks the size constraints, but also strikes a balance between strength and toughness as well as take account of stable thermal shock resistance and oxidation resistance, which realizes strengthening- toughening and oxidation resistance synergy in the true sense. This work provides a strong theoretical and technical support for the engineering applications of 3D carbon fiber toughened UHTC composites.

\section{Acknowledgements}

This work was supported by Key Program of National Natural Science Foundation of China (No. 52032003), National Natural Science Foundation of China (Nos. 51872059 and 51772061), Science Foundation of the National Key Laboratory of Science and Technology on Advanced Composites in Special Environments (No. 6142905202112), China Postdoctoral Science Foundation (No. 2021M690817), and Heilongjiang Provincial Postdoctoral Science Foundation (No. LBH-Z20144).

\section{References}

[1] Li WJ, Huang J, Zhang ZW, et al. Evaluation method and key factor analysis for thermal protection performance of multifunctional integrated ablative materials. Polym Compos 2020, 41: 5043-5058.

[2] Shi YA, Zha BL, Su QD, et al. Thermal performance and ablation characteristics of $\mathrm{C} / \mathrm{C}-\mathrm{SiC}$ for thermal protection of hypersonic vehicle. J Eur Ceram Soc 2021, 41: $5427-5436$.

[3] Zhao YP, Huang HM. Numerical study of hypersonic surface heat flux with different air species models. Acta Astronaut 2020, 169: 84-93.

[4] Yang XF, Gui YW, Xiao GM, et al. Reacting gas-surface interaction and heat transfer characteristics for highenthalpy and hypersonic dissociated carbon dioxide flow. Int J Heat Mass Transf 2020, 146: 118869.

[5] Li Y, Zhang L, He RJ, et al. Integrated thermal protection system based on $\mathrm{C} / \mathrm{SiC}$ composite corrugated core sandwich plane structure. Aerosp Sci Technol 2019, 91: 607-616. 
[6] Jia DC, Liang B, Yang ZH, et al. Metastable Si-B-C-N ceramics and their matrix composites developed by inorganic route based on mechanical alloying: Fabrication, microstructures, properties and their relevant basic scientific issues. Prog Mater Sci 2018, 98: 1-67.

[7] Savino R, Criscuolo L, di Martino GD, et al. Aero-thermochemical characterization of ultra-high-temperature ceramics for aerospace applications. J Eur Ceram Soc 2018, 38: 2937-2953.

[8] Senkov ON, Gorsse S, Miracle DB. High temperature strength of refractory complex concentrated alloys. Acta Mater 2019, 175: 394-405.

[9] Duan LY, Luo L, Liu LP, et al. Ablation of C/SiC-HfC composite prepared by precursor infiltration and pyrolysis in plasma wind tunnel. $J$ Adv Ceram 2020, 9: 393-402.

[10] Cheng YH, Liu YX, An YM, et al. High thermalconductivity $\mathrm{rGO} / \mathrm{ZrB}_{2}-\mathrm{SiC}$ ceramics consolidated from $\mathrm{ZrB}_{2}-\mathrm{SiC}$ particles decorated $\mathrm{GO}$ hybrid foam with enhanced thermal shock resistance. J Eur Ceram Soc 2020, 40: 2760-2767.

[11] Xu BS, Hong CQ, Zhang XH, et al. Nanostructured hybrid carbon nanotube/Ultrahigh-temperature ceramic heterostructures: Microstructure evolution and forming mechanism. J Am Ceram Soc 2015, 98: 3699-3705.

[12] Xu BS, Zhou SB, Hong CQ, et al. Mechanical enhancement of lightweight $\mathrm{ZrB}_{2}$-modified carbon-bonded carbon fiber composites with self-grown carbon nanotubes. Carbon 2016, 102: 487-493.

[13] Du B, Liu HH, Chu YH. Fabrication and characterization of polymer-derived high-entropy carbide ceramic powders. J Am Ceram Soc 2020, 103: 4063-4068.

[14] Philips NR, Carl M, Cunningham NJ. New opportunities in refractory alloys. Metall Mater Trans A 2020, 51: 3299-3310.

[15] Sciti D, Zoli L, Silvestroni L, et al. Design, fabrication and high velocity oxy-fuel torch tests of a $\mathrm{C}_{\mathrm{f}}-\mathrm{ZrB}_{2}$-fiber nozzle to evaluate its potential in rocket motors. Mater Des 2016, 109: 709-717.

[16] Tian S, Zhou L, Liang ZT, et al. 2.5 D carbon/carbon composites modified by in situ grown hafnium carbide nanowires for enhanced electromagnetic shielding properties and oxidation resistance. Carbon 2020, 161: 331-340.

[17] Uhlmann F, Wilhelmi C, Schmidt-Wimmer S, et al. Preparation and characterization of $\mathrm{ZrB}_{2}$ and $\mathrm{TaC}$ containing $\mathrm{C}_{\mathrm{f}} / \mathrm{SiC}$ composites via Polymer-InfiltrationPyrolysis process. J Eur Ceram Soc 2017, 37: 1955-1960.

[18] Zhang ZF, Sha JJ, Zu YF, et al. Fabrication and mechanical properties of self-toughening $\mathrm{ZrB}_{2}-\mathrm{SiC}$ composites from in situ reaction. $J$ Adv Ceram 2019, 8: 527-536.

[19] Li Y, Meng XJ, Jia Y, et al. Properties of $\mathrm{C} / \mathrm{C}-\mathrm{ZrC}$ composites prepared by precursor infiltration and pyrolysis with a meltable precursor. Mater Res Express 2019, 6: 085632.

[20] Tang SF, Hu CL. Design, preparation and properties of carbon fiber reinforced ultra-high temperature ceramic composites for aerospace applications: A review. J Mater Sci Technol 2017, 33: 117-130.

[21] Li Y, Chen SA, Ma X, et al. Influence of preparation temperature on the properties of $\mathrm{C} / \mathrm{ZrC}$ composites. $J$ Alloys Compd 2017, 690: 206-211.

[22] Yoo HI, Kim HS, Hong BG, et al. Hafnium carbide protective layer coatings on carbon/carbon composites deposited with a vacuum plasma spray coating method. $J$ Eur Ceram Soc 2016, 36: 1581-1587.

[23] Li CY, Li GB, Ouyang HB, et al. $\mathrm{ZrB}_{2}$ particles reinforced glass coating for oxidation protection of carbon/carbon composites. J Adv Ceram 2019, 8: 102-111.

[24] Jin XC, Fan XL, Lu CS, et al. Advances in oxidation and ablation resistance of high and ultra-high temperature ceramics modified or coated carbon/carbon composites. $J$ Eur Ceram Soc 2018, 38: 1-28.

[25] Li F, Huang X, Liu JX, et al. Sol-gel derived porous ultra-high temperature ceramics. $J$ Adv Ceram 2020, 9: $1-16$.

[26] Liu HH, Du B, Chu YH. Synthesis of the ternary metal carbide solid-solution ceramics by polymer-derivedceramic route. J Am Ceram Soc 2020, 103: 2970-2974.

[27] Silvestroni L, Kleebe HJ, Fahrenholtz WG, et al. Superstrong materials for temperatures exceeding $2000{ }^{\circ} \mathrm{C}$. Sci Rep 2017, 7: 1-8.

[28] Tong YG, Zhu WT, Bai SX, et al. Thermal shock resistance of continuous carbon fiber reinforced $\mathrm{ZrC}$ based ultra-high temperature ceramic composites prepared via $\mathrm{Zr}$-Si alloyed melt infiltration. Mater Sci Eng: A 2018, 735: 166-172.

[29] $\mathrm{Hu}$ P, Cheng Y, Guo X, et al. Architectural engineering inspired method of preparing $\mathrm{C}_{\mathrm{f}} / \mathrm{ZrC}-\mathrm{SiC}$ with graceful mechanical responses. J Am Ceram Soc 2019, 102: 70-78.

[30] Cheng YH, An YM, Liu YX, et al. $\mathrm{ZrB}_{2}$-based "brick-and-mortar" composites achieving the synergy of superior damage tolerance and ablation resistance. ACS Appl Mater Interfaces 2020, 12: 33246-33255.

[31] Kováčová Z, Bača L', Neubauer E, et al. Influence of sintering temperature, $\mathrm{SiC}$ particle size and $\mathrm{Y}_{2} \mathrm{O}_{3}$ addition on the densification, microstructure and oxidation resistance of $\mathrm{ZrB}_{2}$-SiC ceramics. J Eur Ceram Soc 2016, 36: 3041-3049.

[32] Sha JJ, Zhang ZF, Di SX, et al. Microstructure and mechanical properties of $\mathrm{ZrB}_{2}$-based ceramic composites with nano-sized $\mathrm{SiC}$ particles synthesized by in situ reaction. Mater Sci Eng: A 2017, 693: 145-150.

[33] Kong DW, Wang QY, She TT, et al. Effects of temperature on flexural behavior and flaw sensitivity of $\mathrm{ZrB}_{2}-\mathrm{SiC}$ graphite composite. J Alloys Compd 2019, 773: 905-912.

[34] Shahedi Asl M, Nayebi B, Motallebzadeh A, et al. Nanoindentation and nanostructural characterization of $\mathrm{ZrB}_{2}$-SiC composite doped with graphite nano-flakes. Compos B: Eng 2019, 175: 107153.

[35] Li SJ, Wei CC, Wang WW, et al. Fracture toughness and R-curve behavior of laminated $\mathrm{ZrB}_{2}-\mathrm{SiC} / \mathrm{SiC}_{\mathrm{w}}$ ceramic. $J$ Alloys Compd 2019, 784: 96-101. 
[36] Shahedi Asl M, Azizian-Kalandaragh Y, Ahmadi Z, et al. Spark plasma sintering of $\mathrm{ZrB}_{2}$-based composites co-reinforced with $\mathrm{SiC}$ whiskers and pulverized carbon fibers. Int J Refract Met Hard Mater 2019, 83: 104989.

[37] Baker B, Rubio V, Ramanujam P, et al. Development of a slurry injection technique for continuous fibre ultra-high temperature ceramic matrix composites. J Eur Ceram Soc 2019, 39: 3927-3937.

[38] Zoli L, Vinci A, Galizia P, et al. On the thermal shock resistance and mechanical properties of novel unidirectional UHTCMCs for extreme environments. Sci Rep 2018, 8: 9148.

[39] Hu P, Cheng Y, Zhang DY, et al. From ferroconcrete to Cf/UHTC-SiC: A totally novel densification method and mechanism at $1300{ }^{\circ} \mathrm{C}$ without pressure. Compos B: Eng 2019, 174: 107023.

[40] Hu P, Zhang DY, Dong S, et al. A novel vibration-assisted slurry impregnation to fabricate $\mathrm{Cf} / \mathrm{ZrB}_{2}-\mathrm{SiC}$ composite with enhanced mechanical properties. J Eur Ceram Soc 2019, 39: 798-805.

[41] Leslie CJ, Boakye EE, Keller KA, et al. Development and characterization of continuous $\mathrm{SiC}$ fiber-reinforced $\mathrm{HfB}_{2}$-based UHTC matrix composites using polymer impregnation and slurry infiltration techniques. Int $\mathrm{J} \mathrm{Appl}$ Ceram Technol 2015, 12: 235-244.

[42] Heidenreich B, Bamsey N, Shi Y, et al. Manufacture and test of C/C-SiC sandwich structures. CEAS Space J 2020, 12: 73-84.

[43] Cheng $\mathrm{YH}$. Construction and toughening mechanism of $\mathrm{ZrB}_{2}-\mathrm{SiC}$-graphene biomimetic composite microstructure. Ph.D. Thesis. Harbin (China): Harbin Institute of Technology, 2019.

[44] Gui KX. Low-temperature densification and mechanism of $\mathrm{ZrB}_{2}-\mathrm{SiC}-\mathrm{C}_{\mathrm{sf}}$ composites. Ph.D. Thesis. Harbin (China): Harbin Institute of Technology, 2017.
[45] Davidge RW, Tappin G. The effective surface energy of brittle materials. J Mater Sci 1968, 3: 165-173.

[46] Zimmermann JW, Hilmas GE, Fahrenholtz WG. Thermal shock resistance of $\mathrm{ZrB}_{2}$ and $\mathrm{ZrB}_{2}-30 \%$ SiC. Mater Chem Phys 2008, 112: 140-145.

[47] Sha JJ, Li J, Wang $\mathrm{SH}$, et al. Microstructure and mechanical properties of hot-pressed ZrC-Ti-CNTs composites. Mater Des 2016, 107: 520-528.

[48] Li CY, Li GB, Ouyang HB, et al. Microstructure and properties of $\mathrm{C} / \mathrm{C}-\mathrm{ZrC}$ composites prepared by hydrothermal deposition combined with carbothermal reduction. J Alloys Compd 2018, 741: 323-330.

[49] $\mathrm{Hu} \mathrm{P}$, Gui KX, Hong WH, et al. High-performance $\mathrm{ZrB}_{2}-\mathrm{SiC}-\mathrm{C}_{\mathrm{f}}$ composite prepared by low-temperature hot pressing using nanosized $\mathrm{ZrB}_{2}$ powder. $J$ Eur Ceram Soc 2017, 37: 2317-2324.

[50] $\mathrm{He}$ QC, Lu JH, Wang YW, et al. Effects of joint processes of CLVD and PIP on the microstructure and mechanical properties of $\mathrm{C} / \mathrm{C}-\mathrm{ZrC}$ composites. Ceram Int 2016, 42: 17429-17435.

Open Access This article is licensed under a Creative Commons Attribution 4.0 International License, which permits use, sharing, adaptation, distribution and reproduction in any medium or format, as long as you give appropriate credit to the original author(s) and the source, provide a link to the Creative Commons licence, and indicate if changes were made.

The images or other third party material in this article are included in the article's Creative Commons licence, unless indicated otherwise in a credit line to the material. If material is not included in the article's Creative Commons licence and your intended use is not permitted by statutory regulation or exceeds the permitted use, you will need to obtain permission directly from the copyright holder.

To view a copy of this licence, visit http://creativecommons.org/licenses/by/4.0/. 